\section{Uma revisão de base cienciométrica sobre as Histórias em Quadrinhos no Ensino de Química: uma análise do ENPEC, ENEQ e RASBQ} A scientometric review about comics in chemistry education: analysis ENPEC, ENEQ e RASBQ
congresses

Una revisión cienciométrica sobre historietas en educación química: análisis de congresos ENPEC, ENEQ y RASBQ

\section{Resumo}

A presente pesquisa adota uma investigação quantitativa tendo por objetivo traçar um perfil de base cienciométrica sobre as Histórias em Quadrinhos (HQs) no Ensino de Química em anais de eventos de relevância para a área: Encontro Nacional de Pesquisa em Educação em Ciências (ENPEC), Encontro Nacional de Ensino de Química (ENEQ) e Reunião Anual da Sociedade Brasileira de Química (RASBQ). Os 48 trabalhos encontrados foram analisados a partir de um conjunto de indicadores: gerais, de conteúdo, autoria e referência. Dentre os resultados, destacamos o crescimento temporal de estudos envolvendo HQs; uma paridade entre as principais palavras dos títulos e as palavras-chave; um número excessivo de autores (7 e 8) nos trabalhos; prevalência de artigos e livros nas referências. Nesse sentido, apontamos as pesquisas envolvendo bases cienciométricas como possibilidade para explorar e compreender a produção científica no Ensino de Química e Ciências.

Palavras-Chave: Histórias em Quadrinhos, cienciometria, pesquisa quantitativa.

\begin{abstract}
The present research adopts a quantitative investigation with the objective of tracing a scientometric profile about comics in Chemistry Education in annals of events of relevance to the area: National Meeting of Research in Education in Sciences (ENPEC), National Meeting of Education of Chemistry (ENEQ) and Annual Meeting of the Brazilian Chemical Society (RASBQ). The 48 papers were analyzed based on a set of indicators: general, content, authorship and reference. Among the results, we highlight the temporal growth of studies involving comics; a parity between the main keywords of the titles and the keywords; an excessive number of authors ( 7 and 8 ) in the works; prevalence of articles and books in references. In this sense, we point out the research involving scientometric bases as a possibility to explore and understand the scientific production in the Teaching of Chemistry and Sciences.
\end{abstract}

Keywords: Comics; Scientometric; quantitative investigation.

\section{Resumen}

La presente investigación adopta una investigación cuantitativa con el objetivo de rastrear un perfil cienciométrico sobre historietas en Educación Química en anales de eventos relevantes para el área: Reunión Nacional de Investigación en Educación en Ciencias (ENPEC), Reunión Nacional de Educación de Química (ENEQ) y Reunión Anual de la Sociedad Química Brasileña (RASBQ). Los 48 artículos fueron analizados en base a un conjunto de indicadores: general, contenido, autoría y referencia. Entre los resultados, destacamos el crecimiento temporal de los estudios sobre historietas; una paridad entre las principales palabras clave de los títulos y las palabras clave; un número excesivo de autores ( 7 y 8 ) en las obras; prevalencia de artículos y libros en referencias. En este sentido, señalamos la investigación que involucra bases cienciométricas como una posibilidad para explorar y comprender la producción científica en la Enseñanza de la Química y las Ciencias. Palabras clave: Historietas; Cienciometría; investigación cuantitativa.

\section{AUTORAS:}

ALINE KUNDLATSCH ${ }^{1}$

ORCID 0000-0003-4353-3125

${ }^{1}$ Universidade Estadual

Paulista (UNESP)

BEATRIZ S. C. CORTELA ${ }^{2}$

ORCID 0000-0002-1821-3106

¿Universidade

Estadual Paulista

(UNESP)

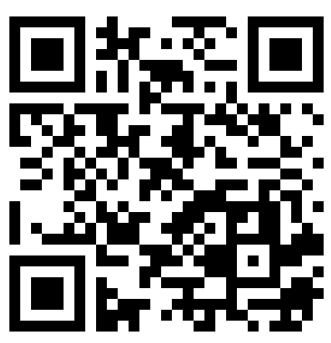

\section{Para citar este artigo:}

KUNDLATSCH, A.; CORTELA, B. S. C. Uma revisão de base cienciométrica sobre as Histórias em Quadrinhos no Ensino de Química: uma análise do ENPEC, ENEQ e RASBQ. Revista Eletrônica Ludus Scientiae, Foz do Iguaçu, v. 02, n. 02, p. 01-13, jul./dez. 2018. 


\section{INTRODUÇÃO}

As Histórias em Quadrinhos (HQs) vêm ganhando destaque como um material promissor, capaz de favorecer processos de ensino e aprendizagem dos estudantes da educação básica. No entanto, um longo caminho foi percorrido pela linguagem quadrinizada para que houvesse a sua inclusão de maneira efetiva no ambiente escolar.

Os primeiros relatos sobre a utilização de HQs com caráter educacional advêm dos Estados Unidos (EUA), durante os anos 40, envolvendo a produção de revistas sobre personagens e eventos históricos. Na mesma década, publicações sobre religião e grandes obras literárias como Charles Dickens, Willian Shakespeare, Victor Hugo foram transpostas em HQs. Os benefícios pedagógicos das HQs começaram a se espalhar pelo Mundo e até mesmo as entidades governamentais apropriaram-se da linguagem gráfica para campanhas educativas, como por exemplo, o governo de Mao Tse-Tung na China e nos EUA durante a Segunda Guerra Mundial (VERGUEIRO, 2014)

A possibilidade das HQs adentrarem o meio educacional começou de maneira tímida, com a sua inclusão em materiais didáticos apenas para ilustrar algum aspecto específico que antes se apresentava em texto. No começo, temia-se pela resistência das escolas em aceitar a sua inserção. Contudo, com o passar do tempo, os resultados foram favoráveis e a incidência de quadrinhos nos livros didáticos aumentou de maneira significativa. Após isso, as barreiras e preconceitos sobre a utilização de HQs no ensino foram diminuindo e o uso desse recurso pelos professores de diferentes disciplinas se expandiu (VERGUEIRO, 2014). No Brasil, abriram-se portas para os quadrinhos a partir da inserção de diferentes linguagens e manifestações artísticas na Lei de Diretrizes e Bases da Educação Nacional (LDB) de 1996 e seu reconhecimento nos Parâmetros Curriculares Nacionais (PCN) e no Programa Nacional Biblioteca na Escola (PNBE) (VERGUEIRO; RAMOS, 2009).

No Ensino de Ciências, alguns autores têm apontado contribuições das HQs para os processos de ensino e aprendizagem de conteúdos científicos escolares (GOMES, 2017; KAWAMOTO; CAMPOS, 2014; SILVA; COSTA, 2015;) e também na formação inicial e continuada de professores (CARUSO; CARVALHO; SILVEIRA, 2005; LEITE, 2017).

Alguns levantamos sobre HQs em revistas e eventos da área de Ensino de Ciência (CAMARGO; RIVELINI-SILVA, 2017; SANTOS; GARCIA, 2017; PIZARRO, 2017) têm mostrado um crescimento expressivo nas pesquisas e uma diversidade de propostas metodológicas envolvendo esses materiais. Apesar dessas investigações trazerem dados quantitativos, o caminho percorrido nos estudos tem um caráter qualitativo, e por isso, não expõem de maneira significativa um panorama e um perfil da produção científica envolvendo a temática.

Como possibilidades para mensurar o desenvolvimento da produtividade científica e as contribuições de um tema ou uma área, podemos utilizar os estudos bibliométricos e cienciométricos. Segundo Macias-Chapula (1998, p. 134), a bibliometria pode ser definida como "[...] o estudo dos aspectos quantitativos da produção, disseminação e uso da informação registrada. [...] desenvolve padrões e modelos matemáticos para medir esses processos, usando seus resultados para elaborar previsões e apoiar tomadas de decisão". No caso da Cienciometria, a sua investigação é baseada nos "[...] aspectos quantitativos da ciência enquanto uma disciplina ou atividade econômica. [...] envolve estudos quantitativos das atividades científicas, incluindo a publicação e, portanto, sobrepondo-se à bibliometria" (MACIAS-CHAPULA, 1998, p. 134). De maneira complementar, Spinak (1998, p. 142, tradução nossa) alega que "[...] a cienciometria aplica técnicas bibliométricas à ciência”.

Para Spinak (1998), os interesses da Cienciometria são diversos, como por exemplo: o crescimento quantitativo da ciência; o desenvolvimento de suas disciplinas; a relação entre ciência e tecnologia; a produtividade dos pesquisadores; as relações entre desenvolvimento científico e crescimento econômico, entre outros. 
Como aponta Tague-Sutckiffe (1992), os estudos cienciométricos são realizados por meio de indicadores quantitativos e aplicação de técnicas matemáticas e estatísticas, de modo que se possa investigar e avaliar a produção científica de uma determinada área do conhecimento. Quanto aos indicadores cienciométricos, Spinak (1998, p. 145) os divide em dois grandes grupos: os de publicação e os de citação. Os indicadores de publicação: medem a quantidade e impacto das publicações científicas" e podem ser subdivididos em: i) extensão bibliométrica (quantidade de artigos por país, instituição, disciplina, entre outros); ii) classificação de revistas por especialistas (primeira, segunda, terceira e quarta classe de revista); iii) indicador de produção (número de artigos, livros, dividido pelo número de autores); iv) indicador de atividade (porcentagem de publicações por autor); v) taxa de crescimento da publicação; vi) distribuição de Bradford (principais revistas); vii) distribuição de Lotka (produtividade dos autores); viii) obsolescência da literatura; ix) distribuição de Zipf (frequência de palavras); e x) distribuição de Waring (potencial das publicações). Os indicadores de citação: medem a quantidade e o impacto das vinculações e as relações entre as publicações científicas, tendo diferentes índices para realizar a mensuração. Entre esses, podemos destacar alguns: i) análise de citação e co-citação; ii) fator de impacto; iii) índice de autocitação; iv) índice de diversidade; v) índice de isolamento, entre outros.

Resumidamente, nas palavras de Razera (2013, p. 2), a "[...] cienciometria identifica e permite analisar uma interessante dimensão das pesquisas que agrega, por exemplo, diferentes perfis indicadores de autores, grupos de pesquisa, produtividade das instituições científicas e tendências das diferentes áreas da ciência”.

No Ensino de Ciências, são poucas as pesquisas que exploram a cienciometria como um referencial teórico-metodológico. Entre essas, se destacam os trabalhos de Razera (2016) que traçou um perfil cienciométrico sobre formação de professores na Revista Ciência \& Educação a partir da análise de 345 artigos, tendo como base os indicadores de produção, autoria, conteúdo e bibliografia. O mesmo autor realizou outro estudo cienciométrico em 380 artigos da Revista Eureka, a partir da temática Ensino e Divulgação da Ciência (RAZERA, 2015). Razera e Jesus (2013) desenvolveram uma investigação sobre a teoria da Aprendizagem Significativa de Ausubel em revistas do Ensino de Ciências, em que foram analisados 1244 artigos a partir dos indicadores de produção e conteúdo.

A partir das premissas expostas, a presente pesquisa tem como objetivo traçar um perfil de base cienciométrica - pesquisa do tipo quantitativa - sobre as Histórias em Quadrinhos no Ensino de Química nos eventos de grande relevância para a área: Encontro Nacional de Pesquisa em Educação em Ciências (ENPEC), Encontro Nacional de Ensino de Química (ENEQ) e Reunião Anual da Sociedade Brasileira de Química (RASBQ), visando compreender e explorar a produção científica sobre essa temática.

\section{PROCEDIMENTOS METODOLÓGICOS}

O presente trabalho adota uma investigação quantitativa com base cienciométrica, em que foram consultados os anais do ENPEC, ENEQ E RASBQ. Em relação ao ENPEC, todas as atas dos 11 eventos (1997-2017) foram consultadas, visto que estão disponíveis no site da Associação Brasileira de Pesquisa em Educação em Ciências (ABRAPEC). No caso do ENEQ, ainda existe dificuldade no acesso às atas antigas, pois estão em formato impresso ou em CD-ROM. Dessa forma, somente analisamos as atas do X ENEQ (2000) até o XVIII ENEQ (2016), última edição realizada até a publicação desse artigo. Sobre as atas da RASBQ também existe a mesma problemática, principalmente por não estarem em formato digital e disponíveis à comunidade científica. Sendo assim, as atas analisadas se restringiram a dez eventos (2007-2016). Vale ressaltar que em 2017, a 40을 RASBQ ocorreu de maneira conjunta com a 46th World Chemistry Congress e IUPAC 49th General Assembly, envolvendo publicações de diferentes países do mundo, e por isso, nosso bloco temporal da RASBQ teve como limite 2016. Dessa forma, a partir da contribuição de todos os eventos, temos um bloco temporal de 20 anos (1997-2017). 
Devido às especificidades do modelo de submissão de trabalhos de cada evento, contemplamos os resumos (uma página) e trabalhos completos (de oito a doze páginas). Para encontramos trabalhos que tivessem como foco as HQs, buscamos pelos descritores: História(s) em Quadrinho(s), quadrinho(s), tirinha(s) e HQ(s) nos títulos, nas palavras-chave e nos resumos. No caso do ENPEC que contempla diferentes áreas das ciências da natureza, todos os trabalhos encontrados foram lidos na íntegra, e aqueles que se remetiam somente ao Ensino de Química foram separados e analisados. Nas atas da RASBQ a busca foi feita somente na seção de Educação Química.

Após a separação dos trabalhos, todos foram baixados no computador, codificados e preparados para a etapa de análise. Para a composição do perfil cienciométrico almejado foram utilizados os indicadores gerais de publicação (quantidade de trabalhos e diacrônica das publicações), de conteúdo (principais palavras nos títulos e nas palavras-chave), autoria (dados de produtividade e autores principais) e referência (tipologia das referências utilizadas). Para a organização e constituição dos dados, alguns softwares foram necessários: um contador de palavras online (http://linguistica.insite.com.br/cgi-bin/corpus/corpus.cgi) e o Microsoft Excel ${ }^{\circledR}$.

\section{RESULTADOS E DICUSSÕES}

Foram encontrados nos referidos eventos 83 trabalhos envolvendo HQs, e desses, 48 com foco no Ensino de Química (Tabela 1), sendo 18 trabalhos completos e 30 resumos.

Tabela 1: Trabalhos encontrados no ENPEC, ENEQ e RASBQ.

\begin{tabular}{|c|c|c|c|c|}
\hline Ano do evento & ENPEC (Geral) & $\begin{array}{c}\text { ENPEC (Ensino de } \\
\text { Química) }\end{array}$ & ENEQ & RASBQ \\
\hline 1997 & o & 0 & - & \# \\
\hline 1999 & o & o & - & $\#$ \\
\hline 2000 & - & - & 0 & $\#$ \\
\hline 2001 & o & o & - & \# \\
\hline 2002 & - & - & 0 & $\#$ \\
\hline 2003 & 1 & o & - & $\#$ \\
\hline 2004 & - & - & 1 & \# \\
\hline 2005 & 1 & $\mathrm{O}$ & - & $\#$ \\
\hline 2006 & - & - & o & $\#$ \\
\hline 2007 & 1 & o & - & o \\
\hline 2008 & - & - & 1 & 1 \\
\hline 2009 & 4 & o & - & 1 \\
\hline 2010 & - & - & 5 & 1 \\
\hline 2011 & 6 & $\mathrm{O}$ & - & 2 \\
\hline 2012 & - & - & 3 & 1 \\
\hline 2013 & 7 & 1 & - & 1 \\
\hline 2014 & - & - & 6 & 1 \\
\hline 2015 & 12 & 3 & - & 4 \\
\hline 2016 & - & - & 13 & o \\
\hline 2017 & 10 & 3 & - & \# \\
\hline TOTAL & 42 & 7 & 29 & 12 \\
\hline
\end{tabular}

Fonte: Autoria própria, 2018.

Nota: Os traços na tabela indicam que o evento não ocorreu naquele ano, o número zero corresponde a nenhum trabalho encontrado e o símbolo jogo da velha indica que a ata daquele ano não foi consultada.

Conforme apresentado na Tabela 1, o ENEQ é o evento que abarca mais contribuições em trabalhos sobre HQs no Ensino de Química (29/48), com destaque para a edição de 2016, em que 13 trabalhos foram identificados. Além disso, foi o primeiro evento a apresentar estudos sobre a temática (em 2004). Em relação a RASBQ, percebemos poucas oscilações em quantidade de número de 
trabalhos por ano, predominando um trabalho por edição. Comparando os três eventos, o ENPEC é o que apresenta a menor contribuição em quantidade de trabalhos sobre as HQs. Os dados da Tabela 1 podem ser melhor visualizados na Figura 1.

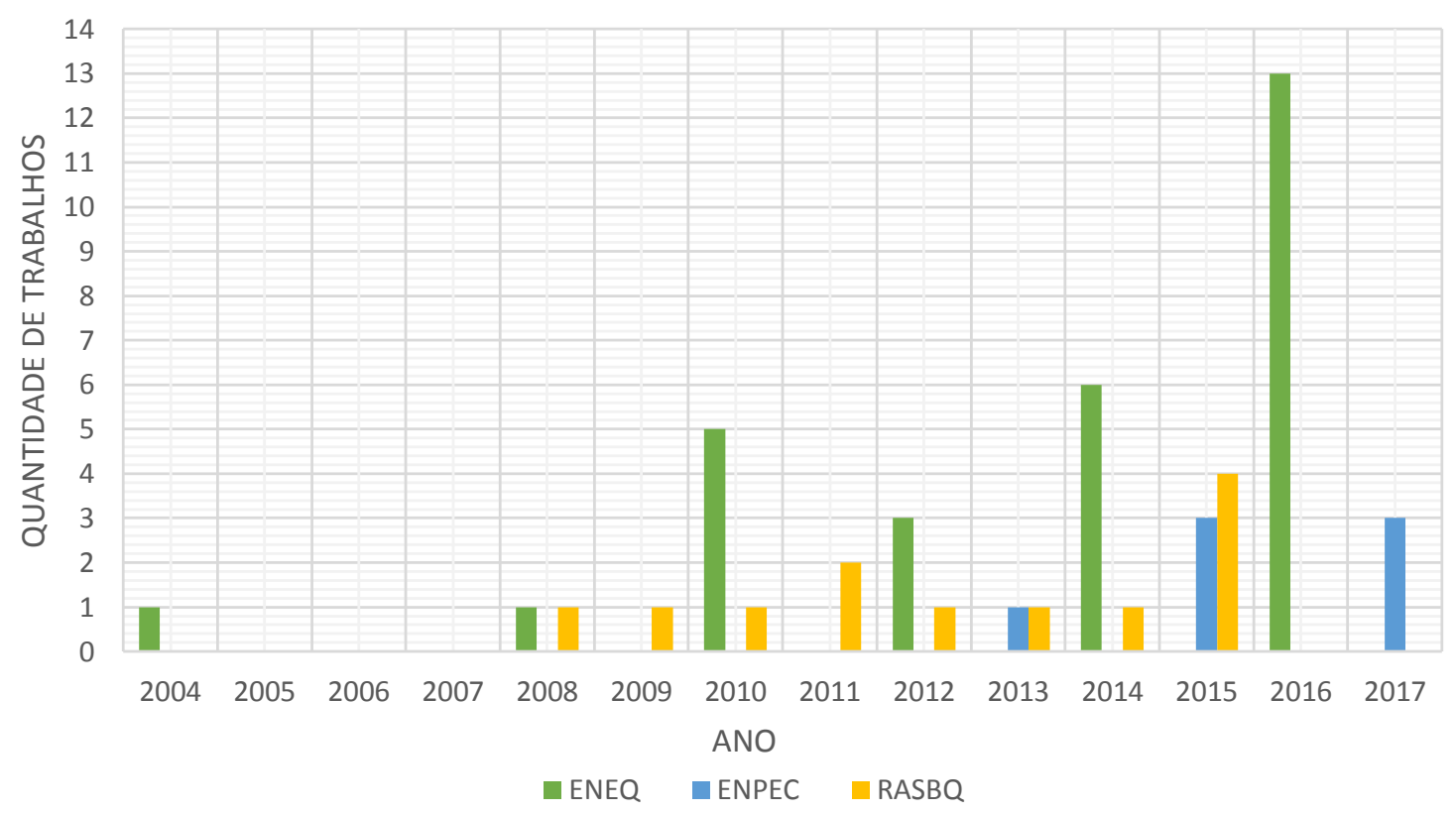

Figura 1: Trabalhos sobre HQs no Ensino de Química encontrados no ENPEC, ENEQ e na RASBQ.

Ainda, com base na Tabela 1, destacamos que nas atas do ENPEC somente foram encontrados trabalhos envolvendo HQs a partir do IV ENPEC (2003), contudo, envolvendo essa temática e o Ensino de Química, os trabalhos só foram identificados 10 anos depois, no IX ENPEC (2013), como pode ser observado na diacrônica da Figura 2. Dessa forma, os trabalhos sobre HQs no Ensino de Química no âmbito desse evento têm uma representatividade de $17 \%$.

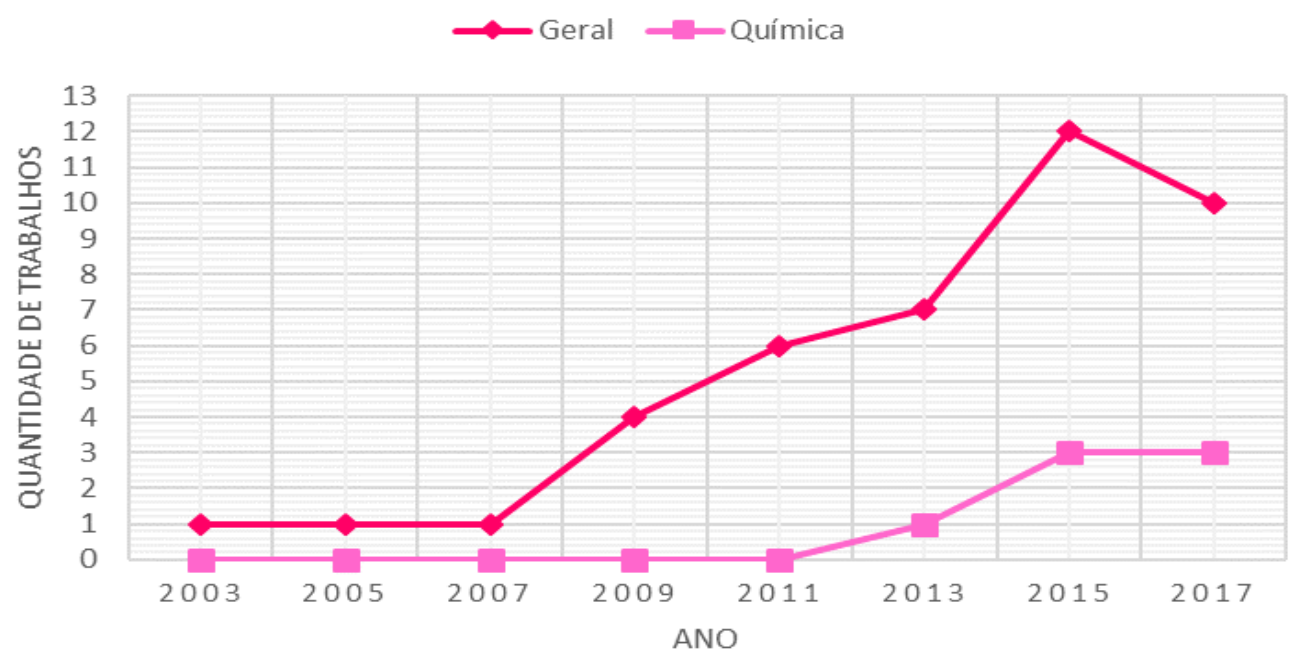

Figura 2: Diacrônica envolvendo os trabalhos sobre HQs no ENPEC.

Dois dos eventos supracitados (ENPEC e ENEQ) apresentam diferentes seções temáticas para a publicação dos trabalhos. Vale ressaltar que no site do XII ENEQ (2004) não havia essa divisão. Dos 
48 trabalhos encontrados, 35 estão distribuídos em seis seções, com predominância na seção Ensino e Aprendizagem (14), como pode ser observado no Quadro 1.

Quadro 1: Quantidade de trabalhos nas seções temáticas do ENPEC e ENEQ.

\begin{tabular}{|c|c|}
\hline Seções temáticas & Quantidade \\
\hline Ensino e Aprendizagem & 14 \\
\hline Materiais educativos & 9 \\
\hline Educação em espaços não-formais e divulgação científica & 7 \\
\hline Linguagens e Discursos & 3 \\
\hline Tecnologias da informação e comunicação & 1 \\
\hline Ensino e Inclusão & 1 \\
\hline TOTAL & 35 \\
\hline
\end{tabular}

Fonte: Autoria própria, 2018.

Em relação ao indicador de conteúdo, nos apropriamos dos fundamentos da Lei de Zipf da Cienciometria, também conhecida como a Lei do Mínimo Esforço, que mede e ordena a frequência de palavras em diferentes textos (SPINAK, 1996), de tal forma que as palavras mais utilizadas indicam o assunto do documento (ARAÚJO, 2006) e tem uma forte correlação com o núcleo da temática estudada (VANTI, 2002). Assim, analisamos as palavras que mais apareceram nos títulos (Quadro 2) e nas palavras-chave (Quadro 3) dos trabalhos.

Quadro 2: Palavras (substantivos e adjetivos) que mais apareceram no título dos trabalhos.

\begin{tabular}{|c|c|}
\hline Palavras & Quantidade \\
\hline Quadrinho (s) & 43 \\
\hline História (s) & 36 \\
\hline Química & 33 \\
\hline Ensino & 27 \\
\hline Proposta & 8 \\
\hline HQ (s) & 6 \\
\hline Produção & 5 \\
\hline Alunos (estudantes) & 4 \\
\hline Divulgação & 4 \\
\hline Aprendizagem & 4 \\
\hline Professores (docentes) & 3 \\
\hline Científica & 3 \\
\hline Ciências & 3 \\
\hline Elementos & 3 \\
\hline Químicos & 3 \\
\hline Recurso & 3 \\
\hline
\end{tabular}

Fonte: Autoria própria, 2018.

Quadro 3: Palavras-chave mais citadas nos trabalhos.

\begin{tabular}{|c|c|}
\hline Palavras-chave & Quantidade \\
\hline Histórias em Quadrinhos & 32 \\
\hline Ensino de Química & 19 \\
\hline HQs & 8 \\
\hline Divulgação Científica & 7 \\
\hline Química & 6 \\
\hline Leitura & 4 \\
\hline Radioatividade & 3 \\
\hline Lúdico & 3 \\
\hline Ensino de Ciências & 2 \\
\hline Ensino não-formal & 2 \\
\hline Linguagem & 2 \\
\hline
\end{tabular}




\begin{tabular}{|c|c|}
\hline Quadrinhos & 2 \\
\hline TIC & 2 \\
\hline Ensino & 2 \\
\hline Alfabetização Científica & 2 \\
\hline EJA & 2 \\
\hline
\end{tabular}

Fonte: Autoria própria, 2018.

Ao todo encontramos 150 palavras-chave, com 68 distintas; dessas, 52 foram utilizadas apenas uma vez. Em relação às palavras dos títulos e as palavras-chaves com maior frequência, percebe-se uma semelhança entre elas. No Quadro 2, dois tipos de sujeitos se destacaram: "professores" e "alunos". No Quadro 3, temos a presença de um conteúdo conceitual da química (Radioatividade), além de um nível de escolaridade (EJA). Além disso, tendo por base o pressuposto de Vanti (2002), podemos inferir que as HQs nesses eventos têm relação com a "Divulgação Científica", "Aprendizagem", "Leitura", "Linguagem”, o "Ensino não-formal”, "Lúdico", as “Tecnologias da Informação (TIC)” e a "Alfabetização Científica”.

Na sequência, apresentamos os dados referentes ao indicador de autoria. Na Tabela 2 está a composição de autores nos trabalhos. Sobre esses, ressalta-se: i) o número excessivo de autores (7 e 8 ) nos trabalhos, mesmo que esses representem somente $4 \%$ do todo e ii) a preponderância de trabalhos com 3, 2 e 5 autores, nesta ordem.

Tabela 2: Composição de autores nos trabalhos.

\begin{tabular}{ccc}
\hline Composição de autores & Quantidade de trabalhos (n) & Quantidade de trabalhos (\%) \\
\hline $\mathbf{1}$ & 3 & $6 \%$ \\
$\mathbf{2}$ & 11 & $23 \%$ \\
$\mathbf{3}$ & 13 & $27 \%$ \\
$\mathbf{4}$ & 6 & $13 \%$ \\
$\mathbf{5}$ & 10 & $21 \%$ \\
$\mathbf{6}$ & 3 & $6 \%$ \\
$\mathbf{7}$ & 1 & $\mathbf{2} \%$ \\
$\mathbf{8}$ & 1 & $\mathbf{2} \%$ \\
TOTAL & $\mathbf{4 8}$ & $\mathbf{1 0 0}, \mathbf{0 0} \%$ \\
\hline
\end{tabular}

Fonte: Autoria própria, 2018.

A Cienciometria compreende três sistemas de contagem para determinação da contribuição dos autores: i) direta: contam-se apenas os autores principais; ii) completa (autores + coautores); e iii) ajustada - a colaboração dos autores é realizada de maneira fracionada, atribuindo a cada autor a sua parcela (URBIZAGÁSTEGUI, 2009). Nesse trabalho analisamos somente os dois primeiros sistemas.

Com base na Lei de Lotka, que trata da produtividade dos autores, e nos estudos de Urbizagástegui (2009), Jesus e Razera (2013) e Razera (2016) organizamos a Tabela 3 com a contribuição em número de trabalhos no sistema da contagem direta e a Tabela 4 de acordo com a contagem completa. Nessa última, adicionamos categorias de produtividade construídas por Urbizagástegui (2009) adaptado de Price (1986). A classificação segue os seguintes critérios: i) Grandes produtores: produzem dez ou mais trabalhos; ii) Produtores moderados: de cinco a nove trabalhos; (iii) Produtores aspirantes: de três a quatro trabalhos; (iv) Produtores transeuntes: de um a dois trabalhos.

Tabela 3: Contribuição em número de trabalhos (contagem direta).

\begin{tabular}{|c|c|c|c|c|c|c|c|}
\hline $\begin{array}{l}\text { Contribuição } \\
\text { em número de } \\
\text { trabalhos }(z)\end{array}$ & $\begin{array}{c}\text { Quantidade } \\
\text { de autores } \\
(\mathbf{n})\end{array}$ & $\begin{array}{c}\text { Quantidade } \\
\text { de trabalhos } \\
\text { (z.n) }\end{array}$ & $\sum \mathbf{z . n}$ & $\begin{array}{c}\text { Quantidade } \\
\text { de autores } \\
(\%)\end{array}$ & $\begin{array}{c}\Sigma(\% \text { de } \\
\text { autores })\end{array}$ & $\begin{array}{l}\text { Quantidade } \\
\text { de trabalhos } \\
\text { (\% de z.n) }\end{array}$ & $\begin{array}{c}\sum(\% \text { de } \\
\text { trabalhos })\end{array}$ \\
\hline 1 & 36 & 36 & 36 & $88 \%$ & $88 \%$ & $75 \%$ & $75 \%$ \\
\hline 2 & 4 & 8 & 44 & $10 \%$ & $98 \%$ & $17 \%$ & $92 \%$ \\
\hline 4 & 1 & 4 & 48 & $2 \%$ & $100 \%$ & $8 \%$ & $100 \%$ \\
\hline TOTAL & 41 & 48 & - & $100 \%$ & - & $100 \%$ & - \\
\hline
\end{tabular}

Fonte: Autoria própria, 2018. 
Na contagem direta (Tabela 3) destacamos alguns aspectos: i) 88\% dos autores produziram apenas 1 trabalho; ii) baixo número de autores (10\%) que elaboraram 2 trabalhos; ii) apenas 1 autor contribuiu com 4 trabalhos; iii) nenhum pesquisador redigiu mais de 4 trabalhos como autor principal.

Tabela 4: Contribuição em número de trabalhos (contagem completa).

\begin{tabular}{ccccc}
\hline Categorias & $\begin{array}{c}\text { Contribuição } \\
\text { em número de } \\
\text { trabalhos } \mathbf{( z )}\end{array}$ & $\begin{array}{c}\text { Quantidade } \\
\text { de autores } \\
(\mathbf{n})\end{array}$ & $\begin{array}{c}\text { Quantidade } \\
\text { de autores } \\
\mathbf{( \% )}\end{array}$ & $\begin{array}{c}\sum(\% \text { de } \\
\text { autores })\end{array}$ \\
\hline $\begin{array}{c}\text { Produtores } \\
\text { transeuntes }\end{array}$ & $\mathbf{2}$ & 108 & $81, \mathbf{2} \%$ & $81, \mathbf{2} \%$ \\
\hline $\begin{array}{c}\text { Produtores } \\
\text { aspirantes }\end{array}$ & 3 & $\mathbf{1 8}$ & $\mathbf{1 3 , 5} \%$ & $94,7 \%$ \\
\hline $\begin{array}{c}\text { Produtores } \\
\text { moderados }\end{array}$ & 5 & 4 & $3,0 \%$ & $97,7 \%$ \\
\hline- & 6 & $\mathbf{2}$ & $\mathbf{1 , 5} \%$ & $99, \mathbf{2} \%$ \\
\hline
\end{tabular}

Fonte: Autoria própria, 2018.

Os dados da Tabela 4 mostram que: i) o alto número de autores $(81,2 \%)$ que produziram um trabalho; ii) um autor contribuiu com seis trabalhos (12,5\% do total); iii) o baixo número de autores (5,3\% do total) com contribuição de três trabalhos ou mais; iv) a prevalência dos produtores transeuntes; e v) a não contemplação da classificação dos Grandes produtores. Price (1963, p. 37 apud Urbizagástegui, 2009, p. 70), aponta que "[...] aproximadamente $75 \%$ daqueles que escrevem um só artigo nunca mais voltam a escrever; e que $10 \%$ dos escritores altamente prolíficos são os que produzem aproximadamente a metade da literatura científica mundial".

Na figura 3, organizamos a distribuição em número de trabalhos por número de autores, de acordo com os dois tipos de contagem (direta e completa).

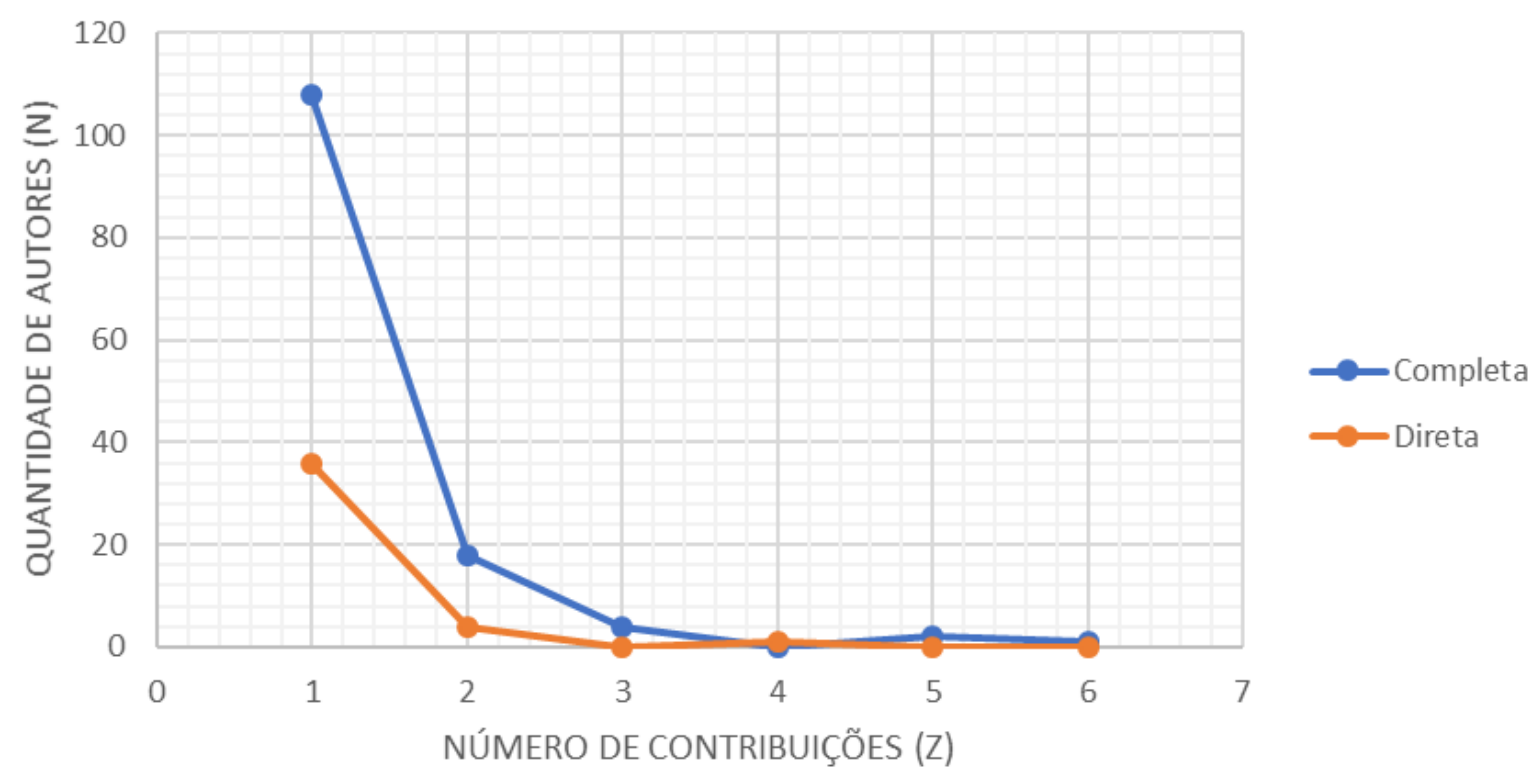

Figura 3: Número de autores versus contribuição em número de trabalhos.

Ressaltamos a partir da Figura 3 uma diferença entre os autores que produziram somente um trabalho com aqueles que produziram dois ou mais. Essa diferença se mostra mais acentuada na 
contagem completa. Contudo, entre os autores que produziram mais de três trabalhos, observa-se uma linearidade no gráfico.

Na sequência, apresentamos a contribuição individual dos autores a partir da contagem direta (Quadro 4) e completa (Quadro 5). Conforme destacamos nos quadros, somente uma autora apareceu em ambas as listas, sendo que na contagem direta apresenta a maior parcela de contribuição.

Quadro 4: Maiores contribuições nos trabalhos (contagem direta).

\begin{tabular}{|c|c|c|}
\hline Autor (a) & $\begin{array}{c}\text { Quantidade de } \\
\text { trabalhos }\end{array}$ & $\begin{array}{c}\text { Quantidade de } \\
\text { trabalhos (\%) }\end{array}$ \\
\hline IWATA, A. Y. & 4 & $8,33 \%$ \\
\hline KUNDLATSCH, A. & 2 & $4,17 \%$ \\
\hline GAMA, E. J. S. & 2 & $4,17 \%$ \\
\hline SANTOS, J. S. & 2 & $4,17 \%$ \\
\hline CRUZ, T. M. G. S. & 2 & $4,17 \%$ \\
\hline
\end{tabular}

Fonte: Autoria própria, 2018.

Quadro 5: Maiores contribuições nos trabalhos (contagem completa).

\begin{tabular}{|c|c|c|}
\hline Autor (a) & $\begin{array}{c}\text { Quantidade de } \\
\text { trabalhos }\end{array}$ & $\begin{array}{c}\text { Quantidade de } \\
\text { trabalhos (\%) }\end{array}$ \\
\hline SOARES, M. H. F. B & 6 & $\mathbf{1 2 , 5} \%$ \\
\hline IWATA, A. Y. & 5 & $10,4 \%$ \\
\hline LUPETTI, K. O. & 5 & $10,4 \%$ \\
\hline SANTOS, A. P. B. & 3 & $6,25 \%$ \\
\hline MOURA, A. F. & 3 & $6,25 \%$ \\
\hline MESQUITA, N. A. S. & 3 & $6,25 \%$ \\
\hline FRANCISCO JUNIOR, W. E. & 3 & $6,25 \%$ \\
\hline
\end{tabular}

Fonte: Autoria própria, 2018.

Em relação a quantidade de referência nos trabalhos, organizamos duas tabelas, uma vez que a quantidade de referências nos resumos (Tabela 5) difere dos trabalhos completos (Tabela 6). Nos resumos identificamos 65 referências, nos trabalhos completos 234, gerando um total de 299 referências.

Tabela 5: Quantidade de referências nos resumos.

\begin{tabular}{ccc}
\hline Número de referências $(\mathbf{n})$ & Quantidade de resumos $(\mathbf{z})$ & Total de referências $\left(\sum \mathbf{z} . \mathbf{n}\right)$ \\
\hline $\mathbf{1}$ & 9 & 9 \\
\hline $\mathbf{2}$ & 11 & $\mathbf{2 2}$ \\
\hline 3 & 7 & 21 \\
\hline 4 & 2 & 8 \\
\hline 5 & $\mathbf{1}$ & 5 \\
\hline TOTAL & $\mathbf{3 0}$ & $\mathbf{6 5}$ \\
\hline
\end{tabular}

Fonte: Autoria própria, 2018.

Tabela 6: Quantidade de referências nos trabalhos completos.

Número de referências (n)

7

8

9

10

11

12
Quantidade de trabalhos completos (z)
Total de referências $\left(\sum z . n\right)$

16

9

20

22

24 


\begin{tabular}{|ccc|}
\hline 13 & 1 & 13 \\
\hline 15 & 1 & 15 \\
\hline 16 & 1 & 16 \\
\hline 17 & 1 & 17 \\
\hline 18 & 2 & 36 \\
\hline 19 & 1 & 19 \\
\hline TOTAL & 1 & 20 \\
\hline Fonter & $\mathbf{1 8}$ & 234 \\
\hline
\end{tabular}

Fonte: Autoria própria, 2018.

As 299 referências foram agrupadas segundo o tipo de obra (Quadro 6). Segundo Alexander e Colaboradores (2009) esse tipo de distinção é importante, pois assim é possível compreender o uso da informação científica.

Quadro 6: Quantidade dos tipos de referências encontradas nos trabalhos.

\begin{tabular}{|c|c|c|}
\hline Tipo de referências & Quantidade & Quantidade (\%) \\
\hline Artigos & 100 & $33,4 \%$ \\
\hline Livros & 82 & $\mathbf{2 7}, 4 \%$ \\
\hline Atas e anais de congresso & 49 & $16,4 \%$ \\
\hline Capítulos de Livros & 21 & $7,0 \%$ \\
\hline Dissertações de mestrado & 15 & $5,0 \%$ \\
\hline Documentos governamentais & 12 & $4,0 \%$ \\
\hline Outros (sites, vídeos, oficinas, relatórios) & 6 & $\mathbf{2 , 0} \%$ \\
\hline Teses de doutorado & 9 & $3,0 \%$ \\
\hline Trabalhos de conclusão de curso & 5 & $\mathbf{1 , 7} \%$ \\
\hline TOTAL & $\mathbf{2 9 9}$ & $\mathbf{1 0 0}, \mathbf{0} \%$ \\
\hline
\end{tabular}

Fonte: Autoria própria, 2018.

Os dados do Quadro 6 apontam a predominância da utilização de artigos nos trabalhos (33,4\%) sobre os demais tipos, contudo, somando os livros e capítulos, a quantidade seria semelhante (103). Tendo em vista essas três fontes juntas, teríamos um equivalente a $67,8 \%$, que mostra a prevalência e relevância dessas referências nos trabalhos. Dados semelhantes foram obtidos por Alexander e colaboradores (2009) e Razera (2016). Em relação aos artigos, Razera (2016, p. 576) afirma que "os periódicos são relevantes ferramentas de difusão de conhecimentos científicos e, quando consolidados, se tornam referências obrigatórias nas suas respectivas áreas".

As atas e os anais de congresso também se destacaram como fontes teóricas nos trabalhos, apresentando um percentual de 16,4\%. Vale destacar a utilização de dissertações (15), teses (9) e trabalhos de conclusão de curso (5), indicando que os autores recorreram as fontes originais de pesquisa com pouca frequência.

Para identificar as principais referências envolvendo HQs, procuramos pelos descritores: quadrinho (s), tirinha (s), HQ (s), comics, historietas. Encontramos 73 referências distintas com algum dos descritores supracitados, e dessas, 69 em português, três em inglês, e uma em espanhol. Considerando as referências mais utilizadas, organizamos o Quadro 7. A partir dos dados expostos, percebemos o predomínio de referências distintas ao Ensino de Química, além da literatura sobre quadrinhos se mostrar ainda recente considerando a sua temporalidade. Por fim, vale mencionar que a fonte teórica mais utilizada foi um trabalho publicado em ata de congresso.

Quadro 7: Referências sobre HQs que mais apareceram nos trabalhos.

\begin{tabular}{|c|c|c|}
\hline Referências & Tipo & Quantidade \\
\hline $\begin{array}{l}\text { PIZARRO, M. V. As Histórias em Quadrinho como Linguagem e } \\
\text { Recurso Didático no Ensino de Ciências. In: VII ENCONTRO }\end{array}$ & $\begin{array}{l}\text { Ata de } \\
\text { congresso }\end{array}$ & 8 \\
\hline
\end{tabular}


NACIONAL DE PESQUISA EM EDUCAÇÃO EM CIÊNCIAS, 7.

Florianópolis. Atas... ABRAPEC: Florianópolis, 2009.

RAMA, A. e VERGUEIRO, W. (Org.) Como usar as Histórias em

Quadrinhos na sala de aula. São Paulo: Contexto, 2008.

CRUZ, T. M. G. S; MESQUITA, N. A. S.; SOARES, M. H. F. B. H' Química

- O uso dos quadrinhos para o Ensino de Radioatividade. In: IX

ENCONTRO NACIONAL DEPESQUISA EM EDUCAÇÃO EM

CIÊNCIAS, 9., 2013, Águas de Lindóia, Atas... ABRAPEC: Águas de Lindóia, 2013

CABELLO, K. S.A; ROCQUE, L; SOUSA FILHO, I. C. Uma história em quadrinhos para o ensino e divulgação da hanseníase, Revista

Electrónica de Enseñanza de las Ciencias, v. 9, n. 1, p. 225-241, 2010.

MC CLOUD, S. Desvendando os Quadrinhos. São Paulo: Makron Books, 1995.

LUYTEN, S. B. História em Quadrinhos. Um recurso de aprendizagem. In: MELLO de SOUZA, M. C. (Org.). História em Quadrinhos um recurso de aprendizagem. Brasília: MEC, 2011.

VERGUEIRO, W.; RAMOS, P. (Orgs.). Quadrinhos na Educação: da rejeição à prática. São Paulo. Editora Contexto. 2009.

TATALOVIC, M. Science comics as tools for science education and communication: a brief, exploratory study. Journal of Science

Communication, v. 8, n. 4, p. 1-17, 2009.

Fonte: Autoria própria, 2018.

\section{CONSIDERAÇÕES FINAIS}

Considerando o perfil cienciométrico almejado, podemos afirmar que os dados são significativos e apontam alguns elementos sobre as HQs no Ensino de Química no âmbito dos eventos da área e um crescimento de pesquisas envolvendo a temática. Percebeu-se a prevalência de trabalhos no ENEQ, seguido pela RASBQ e pelo ENPEC. Esses dados podem indicar, que os trabalhos envolvendo HQs no Ensino de Química ainda são menos vinculados à pesquisa, uma vez que os dois primeiros eventos abarcam, também, relatos de experiência. No caso do ENPEC, foi observada a existência de 42 trabalhos envolvendo HQs, com o primeiro estudo em 2003, no entanto, com enfoque no Ensino de Química, esse número foi reduzido para sete, com a primeira publicação somente em 2013.

Sobre o indicador de conteúdo, percebemos uma paridade entre as principais palavras dos títulos e das palavras-chave, e também algumas tentativas de aproximação da HQs com professores, alunos, EJA, Radioativade, Divulgação Científica, Aprendizagem, Leitura, Linguagem, Ensino nãoformal, lúdico, Tecnologias da Informação (TIC) e Alfabetização Científica. Além disso, a principal palavra-chave utilizada é o próprio termo Histórias em Quadrinhos.

No indicador de autoria, destacamos o número excessivo de autores (7 e 8) nos trabalhos, com uma representatividade $4 \%$ de todos os trabalhos. Em relação a contagem direta dos autores, a maioria produziu apenas um trabalho (88\%) e nenhum elaborou mais de quatro trabalhos como autor principal. Na contagem completa também houve a predominância do número de pesquisadores que redigiram apenas um trabalho $(82,12 \%)$. Somente um autor apresentou contribuição significativa na contagem direta e completa. Também pode-se inferir que, na maioria das vezes, as HQs são usadas de maneira esporádica, e que são poucos os pesquisadores que se dedicam a estudar e publicar pesquisas envolvendo esse recurso.

Em relação ao indicador de referência, houve uma prevalência de artigos e livros (67,8\%). Sobre as fontes de dados mais pontuais envolvendo HQs, essas se mostraram ainda recentes e em desenvolvimento. Ainda há poucas citações de dissertações e teses, reafirmando e se somando às 
pesquisas envolvendo levantamentos, de que estudos envolvendo esse recurso são embrionárias na área de Ensino de Ciências e Química.

Além disso, apontamos pesquisas envolvendo bases cienciométricas como possibilidade para explorar e compreender a produção científica no Ensino de Química e Ciências nos principais eventos da área e periódicos e, de posse destes resultados, prever lacunas sobre temas, aprofundar leituras, e/ou fundamentar novas pesquisas.

\section{AGRADECIMENTOS}

O presente artigo foi realizado com apoio da Coordenação de Aperfeiçoamento de Pessoal de Nível Superior - Brasil (CAPES) - Código de Financiamento oo1.

\section{REFERÊNCIAS}

ALEXANDER, M.; TORRALBO, M.; VALLEJO, M.; FERNÁNDES-CANO, A.; RICO, L. La Educación Matemática en la Revista Enseñanza de las Ciencias: 1983-2006. Enseñanza de las Ciencias, v. 27, n. 2, p. 185-194, 2009.

ARAÚJO, C. A. Bibliometria: evolução histórica e questões atuais. Em Questão, v. 12, n. 1, p. 11-32, 2006.

CAMARGO, S. C.; RIVELINI-SILVA, A. C. Histórias em quadrinhos no ensino de ciências: um olhar sobre o que foi produzido nos últimos doze anos no ENEQ e ENPEC. ACTIO: Docência em Ciências, v. 2, n. 3, p. 133-15o, 2017.

CARUSO, F.; CARVALHO, M.; SILVEIRA, M. C. O. Ensino não-formal no campo das Ciências através dos quadrinhos. Ciência e Cultura, v. 57, n. 4, p. 33-35, 2005.

GOMES, M. G. Confecção de Histórias em Quadrinhos na melhoria do aprendizado de química no ensino médio. REnCiMa, v. 8, n. 2, p. 28-38, 2017.

JESUS, L. G.; RAZERA, J. C. C. Ausubel em trabalhos publicados na área de Educação em Ciências do Brasil: um perfil cienciométrico. Aprendizagem Significativa em Revista/Meaningful Learning Review, v. 3, n. 3, p. 1$12,2013$.

KAWAMOTO, E. M.; CAMPOS, L. M. L. Histórias em Quadrinhos como recurso didático para o ensino do corpo humano em anos iniciais do ensino fundamental. Ciência \& Educação, v. 20, n. 1, p. 147-158, 2014.

LEITE, B. S. Histórias em Quadrinhos e Ensino de Química: Propostas de Licenciandos para uma atividade lúdica. Revista Eletrônica Ludus Scientiae (RELuS), v. 1, n. 1, p. 58-74, 2017.

MACIAS-CHAPULA, C. A. O papel da informetria e da cienciometria e sua perspectiva nacional e internacional. Ciência da Informação, v. 27, n. 2, p. 134-140, 1998.

PIZARRO, M. V. As histórias em quadrinhos e sua relação com o ensino de Ciências: aproximações e reflexos nas dez últimas edições do Encontro Nacional de Pesquisa em Educação em Ciências (ENPEC). In: XI ENCONTRO NACIONAL DE PESQUISA EM EDUCAÇÃO EM CIÊNCIAS, 11. Florianópolis. Atas... ABRAPEC: Florianópolis, 2017 .

RAZERA, J. C. C. A formação de professores em artigos da revista Ciência \& Educação (1998-2014): uma revisão cienciométrica. Ciência \& Educação, v. 22, n. 3, p. 561-583, 2016.

RAZERA, J. C. C. Un perfil cienciométrico de Revista Eureka sobre Enseñanza y Divulgación de las Ciencias (2004-2013). Revista Eureka sobre Enseñanza y Divulgación de las Ciencias, v.12, n. 2, p. 237-248, 2015.

SANTOS, V. J. R. M.; GARCIA, R. N. A pesquisa sobre o uso dos quadrinhos no ensino das Ciências da Natureza apresentadas nos ENPECs de 1997 a 2015. In: XI ENCONTRO NACIONAL DE PESQUISA EM EDUCAÇÃO EM CIÊNCIAS, 11. Florianópolis. Atas... ABRAPEC: Florianópolis, 2017. 
SILVA, E; P.; COSTA, A. B. S. Histórias em Quadrinhos e o Ensino de Biologia: O caso Níquel Naúsea no Ensino da Teoria Evolutiva. Alexandria, v. 8, n. 2, p. 163-182, 2015.

SPINAK, E. Diccionario enciclopédico de bibliometría, cienciometría e informetría. Caracas: Unesco, 1996. 244 p.

SPINAK, E. Indicadores cienciométricos. Ciência da Informação, v. 27, n. 2, p. 141-148, 1998.

TAGUE-SUTCKIFFE, J. An introduction to informetrics. Information Processing \& Management, v. 28, n. 1, p. 1-3, 1992.

URBIZAGÁSTEGUI, R. A. Elitismo na literatura sobre a produtividade dos autores. Ciência da Informação, v. 38, n. 2, p. 69-79, 2009.

VANTI, N. A. P. Da bibliometria à webometria: uma exploração conceitual dos mecanismos utilizados para medir o registro da informação e a difusão do conhecimento. Ciência da Informação, v. 31, n. 2, p. 152-162, 2002.

VERGUEIRO, W. Uso das HQS no Ensino. In: RAMA, A.; VERGUEIRO, W. (Orgs.). Como usar as Histórias em Quadrinhos na sala de aula. São Paulo: Contexto, 2014. p. 7-30.

VERGUEIRO, W.; RAMOS, P. Os quadrinhos (oficialmente) na escola: dos PCN ao PNBE. In: VERGUEIRO, W.; RAMOS, P. (Orgs.). Quadrinhos na Educação: da rejeição a prática. São Paulo: Contexto, 2009. p. 9-42.

Aline Kundlatsch: Licenciada e Bacharela em Química pela Universidade Federal do Paraná (UFPR), câmpus de Curitiba. Durante a graduação, no período de setembro de 2013 a março de 2016 participou como Bolsista do PIBID Química da UFPR. Atualmente, é mestranda do Programa de Pós-Graduação em Educação para a Ciência, na Faculdade de Ciências da Universidade Estadual Paulista Júlio de Mesquita Filho (UNESP), câmpus de Bauru.

E-mail: alinekundlatsch@gmail.com

Beatriz S. C. Cortela: Doutora e Mestre em Educação para Ciência pela Universidade Estadual Paulista Júlio de Mesquita Filho. Licenciada em Matemática (UENP,1985); e licenciada em Pedagogia com Administração Escolar (1995). É membro do Grupo de Pesquisa em Ensino de Ciências, cadastrado no CNPq, interessandose por temas relacionados ao ensino de Ciências e formação de professores (inicial e em serviço) tendo como recortes à docência universitária, metodologias de ensino, programas e as reformas curriculares. É membro do conselho editorial da revista Ciência \& Educação.

E-mail: beatriz.cortela@unesp.br 